\title{
Cosmic ray impact on astrophysical ices: laboratory studies on heavy ion irradiation of methane
}

\author{
A. L. F. de Barros ${ }^{1,4}$, V. Bordalo, ${ }^{2,4}$, E. Seperuelo Duarte ${ }^{2,3}$, E. F da Silveira ${ }^{3}$, \\ A. Domaracka ${ }^{4}$, H. Rothard ${ }^{4}$, and P. Boduch ${ }^{4}$ \\ 1 Departamento de Disciplinas Básicas e Gerais, CEFET-RJ, Av. Maracanã 229, 20271-110 Rio de Janeiro, RJ, Brazil \\ e-mail: abarros@if.ufrj.br \\ 2 Departamento de Física, Pontifícia Universidade Católica do Rio de Janeiro, Rua Marquês de São Vicente 225, \\ 22453-900 Rio de Janeiro, RJ, Brazil \\ 3 Grupo de Física e Astronomia, Instituto Federal do Rio de Janeiro (IFRJ), Rua Lucio Tavares 1045, 26530-060 Nilópolis, \\ RJ, Brazil \\ 4 Centre de Recherche sur les Ions, les Matériaux et la Photonique CIMAP-GANIL (CEA-CNRS-ENSICAEN-UCBN), BP 5133, \\ Boulevard Henri Becquerel, 14070 Caen Cedex 05, France
}

Received 28 October 2010 / Accepted 18 April 2011

\begin{abstract}
Laboratory data of $\mathrm{CH}_{4}$ ice radiolysis promoted by fast heavy ions are obtained by infrared spectroscopy (FTIR). $\mathrm{CH}_{4}$ molecules are condensed on a CsI substrate at $15 \mathrm{~K}$, and the ice layer is bombarded by $220 \mathrm{MeV}^{16} \mathrm{O}^{7+}$ ion beam. The ice thickness is thin enough to be traversed by projectiles at constant velocity close to the equilibrium charge state. The induced $\mathrm{CH}_{4}$ dissociation gives rise to the formation of molecular species $\mathrm{CH}_{3}, \mathrm{C}_{2} \mathrm{H}_{2}, \mathrm{C}_{2} \mathrm{H}_{4}, \mathrm{C}_{2} \mathrm{H}_{6}$, and $\mathrm{C}_{3} \mathrm{H}_{8}$. Their formation and dissociation cross sections are determined. $\mathrm{C}_{2} \mathrm{H}_{6}$ represent the most abundant daughter molecules. The carbon budget analysis of $\mathrm{CH}_{4}$ and its radiolysis products shows that the column density of carbon atoms contained in the methane destroyed during ion irradiation is 30-50\% greater than the sum for the column densities of the newly formed species. As an astrophysical implication, the current results allow estimation of chemical reaction rates in ices covering interstellar grains.
\end{abstract}

Key words. astrochemistry - methods: laboratory - circumstellar matter - ISM: clouds - ISM: molecules

\section{Introduction}

Methane $\left(\mathrm{CH}_{4}\right)$ is one of the the most important condensable volatiles in the solar system. It has been found on the surface of several icy bodies in the Solar System (Cruikshank et al. 1993; Owen et al. 1993; Brown et al. 2005; Licandro et al. 2006), such as the icy clouds of Jovian planets (Lindal et al. 1987; Smith et al. 1989), and of Saturn's moon Titan (McKay et al. 1997; Griffith et al. 1998; Brown et al. 2002), and on the surface of Pluto and of Neptune's satellite Triton (Lanzerotti et al. 1987). Methane ices have also been found throughout the interstellar medium (Lacy et al. 1991; Boogert et al. 1996; Gibb et al. 2004; Öberg et al. 2008). These $\mathrm{CH}_{4}$ containing icy surfaces are exposed to a flux of energetic ions and photons that induce chemical alterations in the bulk (radiolysis and photolysis) and promote erosion at the surface (sputtering). The occurrence of molecular synthesis in these astrophysical ices by cosmic rays, solar wind, UV radiation, and electron collision has been the object of research over the past decades (e.g. Gerakines et al. 1996; Kaiser \& Roessler 1998; Moore \& Hudson 1998; Baratta et al. 2002; Bennett et al. 2006). Heavy galactic cosmic rays (HGCR) are considered as the main agent for keeping a significant fraction of gas phase material in molecular clouds (Leger et al. 1985; Hasegawa \& Herbst 1993; Willacy \& Williams 1993; Bergin et al. 1995; Shematovich et al. 1997; Willacy \& Millar 1998; Nguyen et al. 2002). HGCRs are efficient for desorbing molecules from the surfaces (Seperuelo Duarte et al. 2009, 2010). They also produce secondary UV photons inside the cloud, which may induce the photodesoption of molecules (Öberg et al. 2007, 2009). These desorption mechanisms compete with the gas condensation, thereby setting a steady-state chemistry condition within molecular clouds (Charnley et al. 2001). Irradiation of astrophysical ices, such as $\mathrm{H}_{2} \mathrm{O}, \mathrm{CO}_{2}, \mathrm{CO}$, and $\mathrm{NH}_{3}$, by heavy ions have been recently investigated either by plasma desorption mass spectrometry (Collado et al. 2004; Farenzena et al. 2005; Ponciano et al. 2006; Martinez et al. 2006) or by infrared spectroscopy (FTIR) (Seperuelo Duarte et al. 2009, 2010; Pilling et al. 2010). This kind of data may be useful for estimating desorption rates of the interstellar grains attributed to HGCR (Bringa \& Johnson 2004). In the present contribution, the column densities of $\mathrm{CH}_{4}$ and their radiolysis products have been measured as a function of beam fluence. The ice was irradiated by $220 \mathrm{MeV}{ }^{16} \mathrm{O}^{7+}$ beam and analyzed by FTIR spectrometry. The obtained data allow determination of the destruction cross section of the $\mathrm{CH}_{4}$ and formation cross sections of the main daughter molecules.

\section{Experimental}

The experimental set-up has been described previously (Seperuelo Duarte et al. 2009, 2010; Pilling et al. 2010). In the center of a high vacuum chamber, which is evacuated down to $10^{-8}$ mbar, a closed cycle helium cryostat keeps the CsI substrate at $15 \mathrm{~K}$. To analyze the ice sample, a Nicolet Magna 550 Fourier Transform Infrared Spectrometer running in transmission mode perpendicular to the sample surface was used. Each spectrum 
was acquired by 256 scans from $5000-600 \mathrm{~cm}^{-1}(2-16.7 \mu \mathrm{m})$ with the resolution of $1 \mathrm{~cm}^{-1}$. The ice target was prepared by depositing methane for $1 \mathrm{~min}$ through a $4 \mathrm{~mm}$ diameter tube, placed perpendicular to the substrate, whose extremity was held $10 \mathrm{~mm}$ away. The typical virgin $\mathrm{CH}_{4}$ FTIR spectrum (shown in Fig. 1a) is in good agreement with previous studies (Gerakines et al. 1996; Moore \& Hudson 1998; Kaiser \& Roessler 1998; Bennett et al. 2006). The initial column density of the $\mathrm{CH}_{4}$ before irradiation, $N_{\text {virgin }}=(2.69 \pm 0.50) \times 10^{18}$ molecules $/ \mathrm{cm}^{2}$, was determined by measuring the area of the $v_{1}+v_{4}$ vibration mode band at $4202 \mathrm{~cm}^{-1}$. The Lambert-Beer equation was used for each spectrum on an optical depth scale by the relation for a different absorption $I(v)=I_{0}(v) \exp (-\epsilon(v) N)$, in which $I(v)$ is the intensity of the IR beam after and $I_{0}(v)$ the before absorption at wavenumber $v$. The $\epsilon(v)$ is the wavenumber dependent absorption coefficient (in $\mathrm{cm}^{2}$ ), and $N$ is the column density (molecules per $\mathrm{cm}^{2}$ ). The absorption relation can be rewritten as a function of the absorbance $A^{\prime}(v) \equiv \log \left(\frac{I_{0}(v)}{I(v)}\right)=\frac{\epsilon(v) N}{\ln 10}$.

For normal IR incidence, integration of $A^{\prime}(v)$ over the band width $v_{\mathrm{f}}-v_{i}$ results:

$N=\ln 10 \frac{\int_{v_{i}}^{v_{\mathrm{f}}} A^{\prime}(v) \mathrm{d} v}{A}$,

where $A$ is the integral absorption coefficient (in centimeter per molecule), often referred as " $A$-value". For the $v_{1}+v_{4}$ band, we used $A=3.59 \times 10^{-19} \mathrm{~cm} \mathrm{molecule}^{-1}$ (Brunetto et al. 2008). The $\mathrm{CH}_{4}$ ice layer thickness of $(1.78 \pm 0.10) \mu \mathrm{m}$ has been determined by considering molar mass $16.042 \mathrm{~g} / \mathrm{mol}$ and the density $0.403 \mathrm{~g} / \mathrm{cm}^{3}$ (Brunetto et al. 2008). Figure $1 \mathrm{~b}$ shows a close look at the profiles of $v_{3}$ and $v_{4}$ fundamental bands of the $\mathrm{CH}_{4}$ pure ice film prior to irradiation, which are consistent with that of the crystalline phase II structure with some amorphous features (Chapados \& Cabana 1972; Pearl et al. 1991). Crystallinity of the sample can be verified from the splitting observed in these two fundamental bands (Fig. 1b). The ice layer thickness should be thin enough to be traversed by the projectile with approximately constant velocity and to produce low IR absorbance for keeping Eq. (1) valid; on the other hand, the sample should be thick enough to allow a reliable signal-to-noise ratio for weak FTIR peaks relative to the $\mathrm{CH}_{4}$ daughter species.

To place limits on the maximum ice thickness, the proportionality between the absorbance due to an intense band $\left(3009 \mathrm{~cm}^{-1}\right)$ and the 30 times weaker $\left(4202 \mathrm{~cm}^{-1}\right)$ was verified. The results presented in Fig. 2 show that our sample does not correspond to the saturation regime, therefore the Lambert-Beer law is applicable up to $3 \mu \mathrm{m}$ thick $\mathrm{CH}_{4}$ ice.

The sample was irradiated by $220 \mathrm{MeV}{ }^{16} \mathrm{O}^{7+}$ ions (i.e., $v^{2} \sim$ $14 \mathrm{MeV} / \mathrm{u}$ ions) in a chamber at the medium energy beam line of the heavy ion accelerator GANIL (Grand Accélérateur National d'Ions Lourds). The beam impinged perpendicularly to the sample at constant beam flux $1 \times 10^{9}$ ions $/ \mathrm{cm}^{2} \mathrm{~s}$ up to a final fluence of $4.29 \times 10^{13}$ ions $/ \mathrm{cm}^{2}$. A sweeping device assures a homogeneous irradiation of the sample surface. The stopping power of $220 \mathrm{MeV}$ oxygen projectiles in $\mathrm{CH}_{4}$ is $76.5 \times 10^{-15} \mathrm{eV} / \mathrm{molecule} / \mathrm{cm}^{2}$ (SRIM) (Ziegler et al. 1985), and the total energy loss per projectile in the ice layer was about $206 \mathrm{keV}$. This amount is negligible with respect to initial energy. Therefore, cross sections do not change with ion penetration depth. Beyond the ice target, the beam was stopped in the $2 \mathrm{~mm}$ thick CsI substrate. The dose absorbed by the $\mathrm{CH}_{4}$ is estimated to be $3.3 \mathrm{eV}$ per molecule at the end of irradiation.
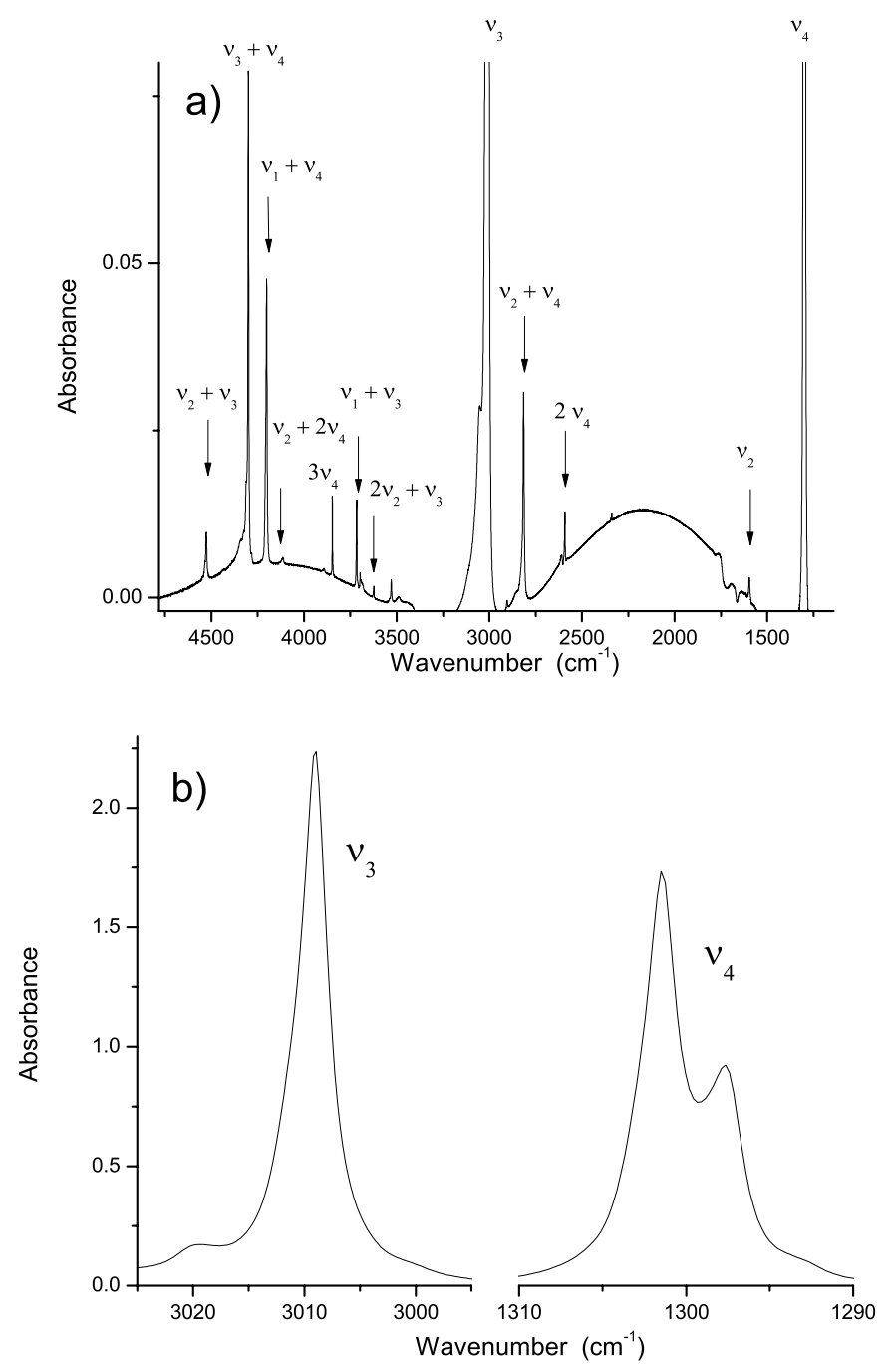

Fig. 1. Infrared spectrum of the methane ice at $15 \mathrm{~K}$, before irradiation. In a) the absorbance scale has been enlarged to make the less intense combination bands of all $\mathrm{CH}_{4}$ assignments visible and b) zoom of the $v_{3}$ (this band is slightly saturated, but it does not significantly change the band profile) and $v_{4}$ assignments. The vibration modes at 1302 and $1298 \mathrm{~cm}^{-1}$ are considered as centered at $1300 \mathrm{~cm}^{-1}$.

\section{Results}

The effect of irradiation on $\mathrm{CH}_{4}$ is illustrated in Figs. 3a and b, where relevant sections of the FTIR spectra acquired before and after irradiation are compared.

\subsection{Identification of IR bands}

Five $\mathrm{CH}_{4}$ IR absorptions bands can be identified: i) the fundamental deformation mode $\left(v_{4}\right)$ centered at $1300 \mathrm{~cm}^{-1}$; ii) three vibrations combinations bands: $\left(v_{3}+v_{4}\right), 4300 \mathrm{~cm}^{-1},\left(v_{1}+v_{4}\right)$ at $4202 \mathrm{~cm}^{-1}$ and another $\left(v_{2}+v_{4}\right)$ at $2815 \mathrm{~cm}^{-1}$; and iii) a second fundamental stretching peak $\left(v_{3}\right)$ centered at $3009 \mathrm{~cm}^{-1}$. The $\mathrm{CH}_{4}$ column density dependence on beam fluence is presented in Fig. 4. The simultaneously analysis of five different bands may help for obtaining a correct column density value. Indeed this proposed procedure allow us to (i) examine possible saturation in the detector; (ii) check whether other species contribute to the analyzed peak; and/or (iii) observe possible phase transition. Moreover, the internal normalization provides consistency among $A$-values for the five bands in the column density 
A. L. F. de Barros et al.: Cosmic ray impact on astrophysical ices

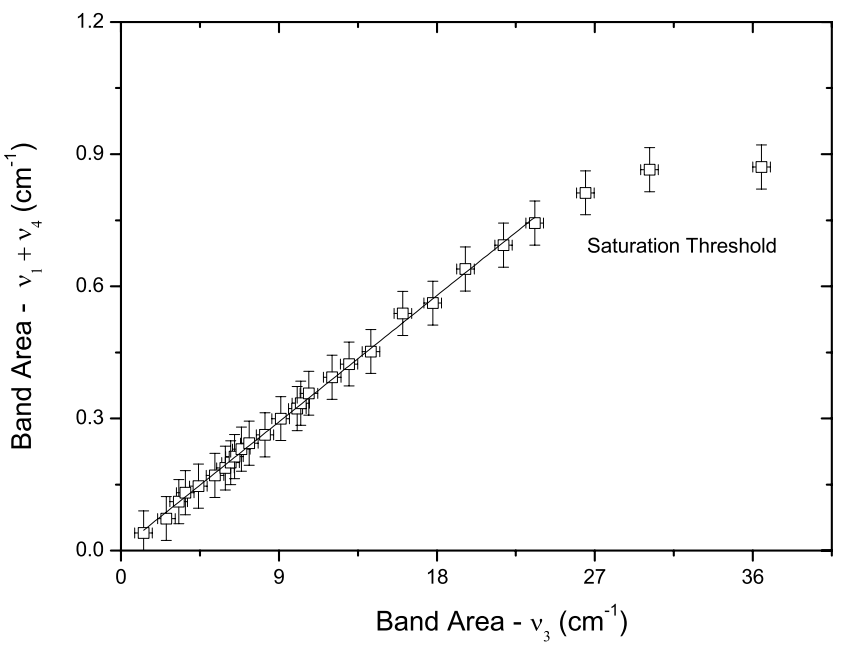

Fig. 2. Comparison between the increase of band areas corresponding to the $\left(v_{1}+v_{4}\right)-4202$ and $\left(v_{3}\right)-3009 \mathrm{~cm}^{-1}$ transitions of $\mathrm{CH}_{4}$ during continuous ice deposition at $15 \mathrm{~K}$.
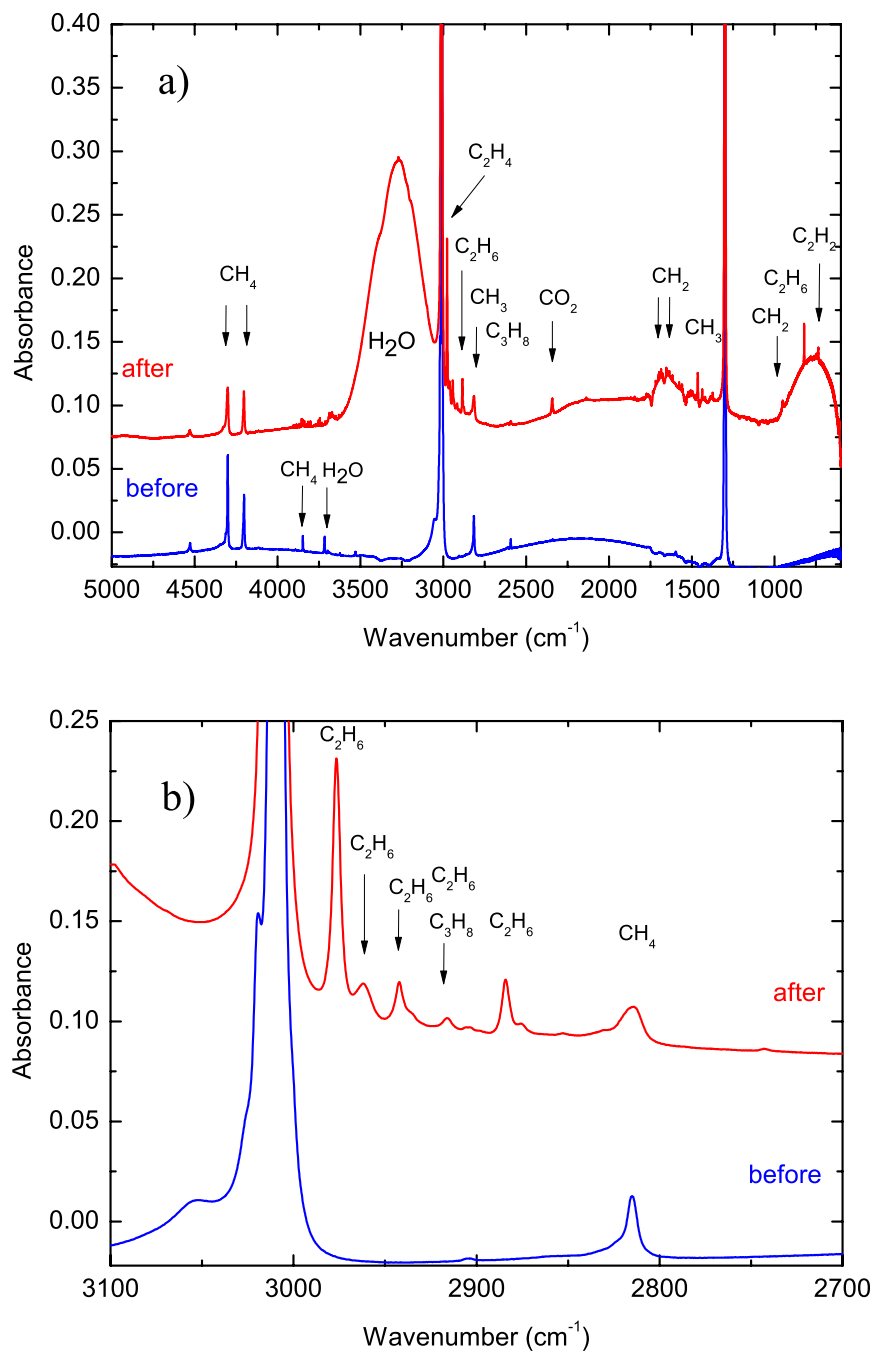

Fig. 3. Comparison of FTIR spectra regions of the $\mathrm{CH}_{4}$ ice at $15 \mathrm{~K}$ before (lower) and after (upper) irradiation. The spectrum corresponds to a final fluence of $4.29 \times 10^{13} \mathrm{ions} / \mathrm{cm}^{2}$. a) Range of $600-5000 \mathrm{~cm}^{-1}$ and b) range of $2700-3100 \mathrm{~cm}^{-1}$.

calculation. From this analysis, the band $4202 \mathrm{~cm}^{-1}$ was selected as the reference feature (see Sect. 3.2.2).
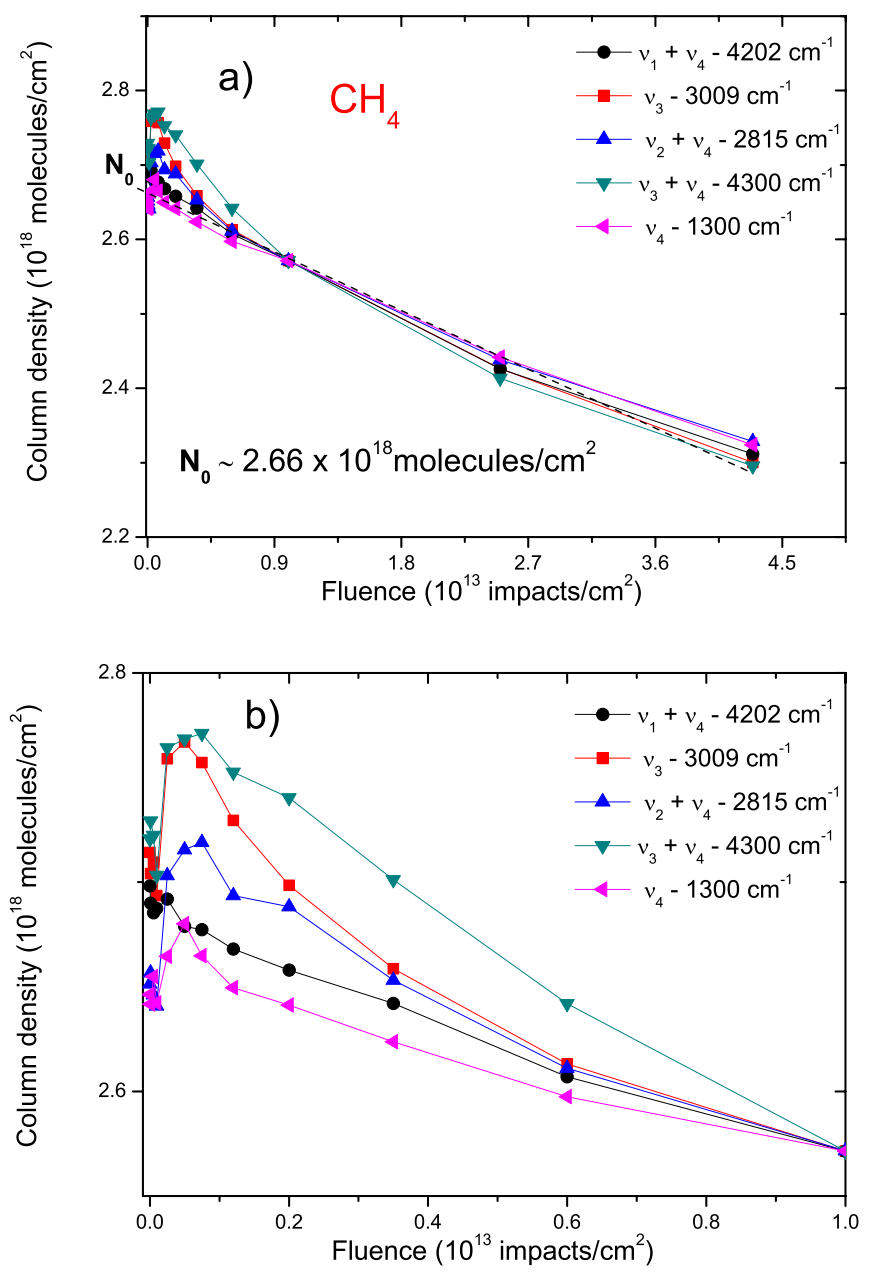

Fig. 4. a) Comparison of the $\mathrm{CH}_{4}$ column densities evolution obtained from the analysis of five IR transitions normalized to the band $4202 \mathrm{~cm}^{-1}$ at $F=1.0 \times 10^{13}$ impacts $/ \mathrm{cm}^{2}$. b) At lower fluences, there are differences among the column density absolute values, as discussed in Sect. 3.2.1 on the $\mathrm{CH}_{4}$ analysis.

In Table 1, the band position, assignments, and characterization of all the observed vibration modes of $\mathrm{CH}_{4}$ daughters are compared with those of the literature. A very small initial contamination of $\mathrm{CO}_{2}\left(v_{3}-2346 \mathrm{~cm}^{-1}\right), \mathrm{CO}\left(2138 \mathrm{~cm}^{-1}\right)$, and $\mathrm{H}_{2} \mathrm{O}$ bands $3714 \mathrm{~cm}^{-1}$ and $3255 \mathrm{~cm}^{-1}$ (Ehrenfreund et al. 1996) are also observed.

\subsection{Column density determination}

The knowledge of the $A$-value is crucial for determining of the correct column density, as related in Eq. (1). The $A$-values available in the literature may not be adequate for a particular target, since these values may change with ice temperature and crystalline phase. Two tests should be considered in this analysis:

(i) For a given molecular species, the consistency of the relative values of $A$ due to its distinct bands can be checked by verifying that the same column density is obtained from the respective absorbance bands (see Figs. 4 and 5).

(ii) For the precursor species and its daughter species, the consistency of their $A$ relative values can be checked by the socalled carbon budget test (Bennett et al. 2006): if no sputtering of these species occurs, the total number of carbon 
Table 1. Comparison of peak positions, assignments, and characterizations of $\mathrm{CH}_{4}$ daughter molecules at $220 \mathrm{MeV}^{16} \mathrm{O}^{+7}$, a fluence of $4.29 \times$ $10^{19}$ ions $/ \mathrm{cm}^{2}$.

\begin{tabular}{|c|c|c|c|c|}
\hline $\begin{array}{l}\text { Position }\left(\mathrm{cm}^{-1}\right) \\
\text { this work }\end{array}$ & Assignment & Molecules & Characterization & Reference \\
\hline 4165 & - & - & - & - \\
\hline 4070 & - & - & - & - \\
\hline 3267 & $v_{3}$ & $\mathrm{C}_{2} \mathrm{H}_{2}$ & $\mathrm{CH}$ stretch & $2,3,4$ \\
\hline 3248 & $v$ & $\mathrm{H}-\mathrm{C} \equiv \mathrm{C}-\mathrm{R}$ & $(\mathrm{C}-\mathrm{H})$ & 1 \\
\hline 3150 & $v_{3}$ & $\mathrm{CH}_{3}$ & $\mathrm{CH}$ stretching & 4 \\
\hline 3095 & $v_{9}$ & $\mathrm{C}_{2} \mathrm{H}_{4}$ & $\mathrm{CH}_{2}$ asym. str. & 3,4 \\
\hline 2975 & $v_{10}$ & $\mathrm{C}_{2} \mathrm{H}_{6}$ & $\mathrm{CH}_{3}$ deg. str. & $1,3,4$ \\
\hline \multirow[t]{3}{*}{2962} & $v_{1}$ & $\mathrm{C}_{2} \mathrm{H}_{6}$ & $\mathrm{CH}_{3}$ sym. str. & 4 \\
\hline & $v_{11}$ & $\mathrm{C}_{2} \mathrm{H}_{4}$ & - & 2 \\
\hline & $v_{\mathrm{as}}$ & $\mathrm{R}-\mathrm{CH}_{3}$ & $(\mathrm{C}-\mathrm{H})$ & 1 \\
\hline 2941 & $v_{8}+v_{11}$ & $\mathrm{C}_{2} \mathrm{H}_{6}$ & Combination & 4 \\
\hline 2935 & $v_{\mathrm{as}}$ & $\mathrm{R}-\mathrm{C}_{2}-\mathrm{R}$ & $(\mathrm{CH})$ & 1 \\
\hline \multirow[t]{2}{*}{2915} & $v_{8}+v_{11}$ & $\mathrm{C}_{2} \mathrm{H}_{6}$ & Combination & 4 \\
\hline & - & $\mathrm{C}_{3} \mathrm{H}_{8}$ & - & 1 \\
\hline 2884 & $v_{5}$ & $\mathrm{C}_{2} \mathrm{H}_{6}$ & $\mathrm{CH}_{3}$ sym. str. & $1,3,4$ \\
\hline 2874 & $v_{\mathrm{s}}$ & $\mathrm{R}-\mathrm{CH}_{3}$ & $(\mathrm{CH})$ & 1,2 \\
\hline 2850 & $v_{8}$ & $\mathrm{R}-\mathrm{CH}_{2}-\mathrm{R}$ & $(\mathrm{C}-\mathrm{H})$ & 1 \\
\hline 2744 & - & - & - & - \\
\hline 2651 & - & - & - & - \\
\hline 2611 & - & - & - & - \\
\hline 2593 & - & - & - & - \\
\hline 1645 & - & - & - & - \\
\hline 1463 & $v_{11}$ & $\mathrm{C}_{2} \mathrm{H}_{6}$ & $\mathrm{CH}_{3}$ d-deform & $1,3,4$ \\
\hline 1436 & $v_{12}$ & $\mathrm{C}_{2} \mathrm{H}_{4}$ & $\mathrm{CH}_{2}$ scissor & $2,3,4$ \\
\hline 1387 & $v_{4}+v_{5}$ & $\mathrm{C}_{2} \mathrm{H}_{2}$ & - & 2 \\
\hline \multirow[t]{2}{*}{1375} & $v_{6}$ & $\mathrm{C}_{2} \mathrm{H}_{6}$ & $\mathrm{CH}_{3}$ sym. def. & $1,3,4$ \\
\hline & $\delta_{8}$ & $\mathrm{C}_{3} \mathrm{H}_{8}$ & $\mathrm{R}-\mathrm{CH}_{3}$ & 1 \\
\hline 952 & $v_{7}$ & $\mathrm{C}_{2} \mathrm{H}_{4}$ & $\mathrm{CH}_{2}$ wag & 2,4 \\
\hline 911 & - & $\mathrm{R}_{2} \mathrm{C}=\mathrm{CH}_{2}$ & $\delta(\mathrm{CH})$ out-of-plane & 1 \\
\hline \multirow[t]{2}{*}{821} & $v_{12}$ & $\mathrm{C}_{2} \mathrm{H}_{6}$ & $\mathrm{CH}_{3}$ rock & $1,3,4$ \\
\hline & $v_{9}$ & $\mathrm{C}_{2} \mathrm{H}_{6}$ & - & 2 \\
\hline 750 & - & $\mathrm{C}_{3} \mathrm{H}_{8}$ & - & 1 \\
\hline 736 & $v_{5}$ & $\mathrm{C}_{2} \mathrm{H}_{2}$ & $\mathrm{CH}$ bend & 2,4 \\
\hline 608 & $v_{2}$ & $\mathrm{CH}_{3}$ & Out of plane & $1,2,3,4$ \\
\hline
\end{tabular}

References. (1) Gerakines et al. (1996), (2) Kaiser et al. (1998), (3) Moore et al. (2003), and (4) Bennett et al. (2006).

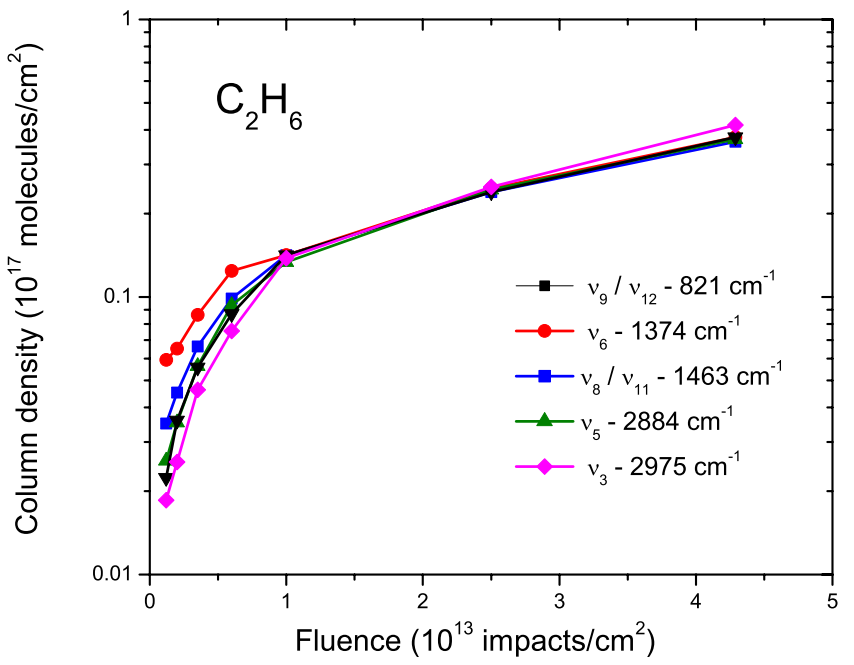

Fig. 5. Column density dependence of $\mathrm{C}_{2} \mathrm{H}_{6}$ daughters molecules on beam fluence. Solid lines are guides for the eyes. See Sect. 3.2.2 for further discussion of the dispersion observed at low fluences.

atoms must stay constant during irradiation regardless of the chemical reactions induced by radiation.
Based on this, the destruction rate of $\mathrm{CH}_{4}$ must be at any time equal to or greater than the sum of formation rates of its daughter molecules (because some of formed species cannot be observed by FTIR) (see Sect. 3.5).

\subsection{1. $\mathrm{CH}_{4}$ analysis}

For the current $\mathrm{CH}_{4}$ data, the two tests revealed problems with the $A$-values found in the literature. To find coherent $A$-values, the column densities of all the others $\mathrm{CH}_{4}$ transitions were normalized to the band $4202 \mathrm{~cm}^{-1}$ over a high fluence region $\left(F=1.0 \times 10^{13}\right.$ ions $\left./ \mathrm{cm}^{2}\right)$, assuming that the $A$-value reported by (Brunetto et al. 2008) is the correct one. The normalized $A$-values obtained are displayed in the last column of Table 2.

The effect of this normalization is presented in Fig. 4a for the whole fluence range and in Fig. $4 \mathrm{~b}$ for the low fluence region. It is observed that all the curves have the same slope at high fluence, showing that the corresponding column densities are proportional to that of the $4202 \mathrm{~cm}^{-1}$ band. In contrast, this is not the case for low fluence where data are scattered. There are different ways to express this finding: (i) the structure of ice is changing; (ii) the $A$-value for a virgin ice is not the same as for a high-fluence regime when the ice phase is already stable; and (iii) the relative variations in the $A$-value for distinct IR bands of 
Table 2. Comparisons of the integral absorption coefficient $A\left(10^{-18} \mathrm{~cm}\right.$ molecule $\left.{ }^{-1}\right)$ used in the current work with those reported in literature for the $\mathrm{CH}_{4}$ and for its products formed by the heavy ion irradiation.

\begin{tabular}{|c|c|c|c|c|c|c|c|c|}
\hline Molecule & $\begin{array}{l}\text { Position } \\
\mathrm{cm}^{-1}\end{array}$ & $\begin{array}{l}\text { Mulas et al. } \\
\text { (1998) }\end{array}$ & $\begin{array}{l}\text { Moore et al. } \\
\text { (1998) }\end{array}$ & $\begin{array}{l}\text { Kaiser et al. } \\
\text { (1998) }\end{array}$ & $\begin{array}{l}\text { Gerakines et al. } \\
\text { (1996) }\end{array}$ & $\begin{array}{l}\text { Gerakines et al. } \\
\text { (2005) }\end{array}$ & $\begin{array}{l}\text { Brunetto et al. } \\
\text { (2008) }\end{array}$ & This work* \\
\hline \multirow[t]{5}{*}{$\mathrm{CH}_{4}$} & 4300 & - & - & 3.5 & - & 3.4 & 0.69 & 0.43 \\
\hline & 4202 & - & - & 1.6 & - & 1.6 & 0.36 & 0.36 \\
\hline & 3009 & 9.5 & - & - & 6.4 & - & - & 10.5 \\
\hline & 2815 & - & - & - & - & 1.9 & 0.28 & 0.26 \\
\hline & 1300 & 6.4 & 6.63 & 6.2 & 6.1 & 7.0 & - & 7.76 \\
\hline $\mathrm{CH}_{3}$ & 608 & - & - & 25 & 25 & - & - & 25 \\
\hline \multirow[t]{2}{*}{$\mathrm{C}_{2} \mathrm{H}_{2}$} & 736 & - & - & 14 & - & - & - & 14 \\
\hline & 3267 & - & - & 32 & - & - & - & 32 \\
\hline \multirow[t]{3}{*}{$\mathrm{C}_{2} \mathrm{H}_{4}$} & 952 & - & - & 15 & - & - & - & 15 \\
\hline & 1436 & - & 2.93 & - & 0.85 & - & - & 1.2 \\
\hline & 3095 & - & - & 1.0 & - & - & - & 1.0 \\
\hline \multirow[t]{5}{*}{$\mathrm{C}_{2} \mathrm{H}_{6}$} & 821 & - & - & 1.9 & - & - & - & 1.9 \\
\hline & 1463 & - & 4.16 & 2.7 & - & - & - & 2.5 \\
\hline & 1375 & - & - & 0.6 & - & - & - & 0.33 \\
\hline & 2884 & - & 4.39 & - & - & - & - & 3.2 \\
\hline & 2975 & - & 10.5 & - & 6.5 & - & - & 14.8 \\
\hline $\mathrm{C}_{3} \mathrm{H}_{8}$ & 2962 & - & 15.8 & - & - & - & - & 15.8 \\
\hline
\end{tabular}

Notes. ${ }^{(*)}$ The $A$-values in bold refer to literature data that have been used in this work for the calculation of the cross sections. For the other vibration modes, the displayed values (not in bold) were obtained by normalization of $N(F)$ (Sect. 3.2.1). All values are obtained from transmission mode spectroscopy.

the same molecular species are different from each other in the low-fluence region.

It follows from this analysis that the initial column density of $\mathrm{CH}_{4}$ measured by FTIR spectrum of the virgin ice $\left(N_{\text {virgin }}=2.69 \times 10^{18}\right.$ molecules $\left./ \mathrm{cm}^{2}\right)$ is in good agreement inside the error bar, with $N_{0}=2.66 \times 10^{18}$ molecules $/ \mathrm{cm}^{2}$ obtained from extrapolating high-fluence data towards $F=0$. It can be verified that the current normalized $A$-values are in fair agreement with the work of Brunetto et al. (2008), Mulas et al. (1998) (band $3009 \mathrm{~cm}^{-1}$ ), and Gerakines et al. (2005) (band $1300 \mathrm{~cm}^{-1}$ ). For the carbon budget calculation, we assume that the band at $4202 \mathrm{~cm}^{-1}\left(v_{1}+v_{4}\right)$ is the adequate one, as described in Sect. 3.5.

\subsubsection{Daughter species analysis}

The $A$-values for the molecular species produced under irradiation of the $\mathrm{CH}_{4}$ ice are also displayed in Table 2. Data for them are scarce, so we adopted some of the available values in literature (Table 2). In the case of disagreement between two bands for the column density determination, normalization to a reference band at $F=1.0 \times 10^{13}$ ions $/ \mathrm{cm}^{2}$ was carried out, following the same procedure as for the $\mathrm{CH}_{4}$ analysis.

The appearance of the methyl radical $\mathrm{CH}_{3}$ is observed via its $v_{2}$ vibration at the top of intense band at $608 \mathrm{~cm}^{-1}$. For this band we adopted the $A$-value $\left(25 \times 10^{-18} \mathrm{~cm}\right.$ molecule $\left.{ }^{-1}\right)$ previously reported by Gerakines et al. (1996), Moore \& Hudson (2003), and Kaiser \& Roessler (1998).

Four stable daughter species also appeared during irradiation: $\mathrm{C}_{2} \mathrm{H}_{2}, \mathrm{C}_{2} \mathrm{H}_{4}, \mathrm{C}_{2} \mathrm{H}_{6}$, and $\mathrm{C}_{3} \mathrm{H}_{8}$. Vibration modes of the $\mathrm{C}_{2} \mathrm{H}_{2}$ molecule at $736 \mathrm{~cm}^{-1}$ and $3267 \mathrm{~cm}^{-1}$ have been commonly attributed to the $v_{5}$ and $v_{3}$ vibration modes, therefore we assume the same $A$-value in the literature such as the $A=$ $14 \times 10^{-18} \mathrm{~cm}$ molecule ${ }^{-1}$ (Moore \& Hudson 1998; Kaiser \& Roessler 1998) and $A=32 \times 10^{-18} \mathrm{~cm}$ molecule ${ }^{-1}$ (Kaiser \& Roessler 1998), respectively. The molecule $\mathrm{C}_{2} \mathrm{H}_{4}$ is identified by the bands at $952 \mathrm{~cm}^{-1}$ and $3095 \mathrm{~cm}^{-1}$, which rise at the beginning of the irradiation. We also used for those bands the values available in literature such as $A=15 \times$ $10^{-18} \mathrm{~cm}$ molecule ${ }^{-1}$ and $1.0 \times 10^{-18} \mathrm{~cm}$ molecule ${ }^{-1}$ (Moore $\&$ Hudson 1998; Kaiser \& Roessler 1998), respectively. For those bands, the $A$-values agree with each other, differing for the $v_{12}$ vibration mode at $1436 \mathrm{~cm}^{-1}$. The band $1436 \mathrm{~cm}^{-1}$ has been normalized to the band $952 \mathrm{~cm}^{-1}$ (see Table 2). For $\mathrm{C}_{3} \mathrm{H}_{8}$ vibration mode $v_{1}$ at a peak at $2962 \mathrm{~cm}^{-1}$, the attributed $A$-value was the only the available in the literature: $15.8 \times 10^{-18} \mathrm{~cm} \mathrm{molecule}^{-1}$ (Moore \& Hudson 1998).

The $\mathrm{C}_{2} \mathrm{H}_{6}$ molecule is the most abundant daughter species formed; this molecule is identified through its $v_{12}, v_{11}, v_{6}, v_{5}$, and $v_{10}$ vibrations at $821 \mathrm{~cm}^{-1}$ (Kaiser \& Roessler 1998), $1463 \mathrm{~cm}^{-1}$ (Moore \& Hudson 1998; Kaiser \& Roessler 1998), $1375 \mathrm{~cm}^{-1}$, $2884 \mathrm{~cm}^{-1}, 2975 \mathrm{~cm}^{-1}$ (Kaiser \& Roessler 1998), respectively. The $A$-values for $\mathrm{C}_{2} \mathrm{H}_{6}$ bands displayed in the last column of Table 2 were determined from the normalization to the band at fluence $=1.0 \times 10^{13}$ ions $/ \mathrm{cm}^{2}$. For this band $\left(821 \mathrm{~cm}^{-1}\right)$ we adopted the value $A=1.9 \times 10^{-18} \mathrm{~cm}$ molecule ${ }^{-1}$ used by (Kaiser \& Roessler 1998). For the carbon budget test, described in Sect. 3.4, we have adopted this band. From Fig. 5, it can be noticed that the shapes for all the vibration modes agree quite closely. The change in the interaction of newly formed $\mathrm{C}_{2} \mathrm{H}_{6}$ molecules with the surrounding environments (matrix effect) that is evolving, under irradiation, both structurally and chemically may the responsible for the absolute value dispersion observed at low fluences.

The $\mathrm{C}_{2} \mathrm{H}_{5}$ transition at band $534 \mathrm{~cm}^{-1}$ is out of range of the current FTIR spectrometer so could not been observed. The $\mathrm{C}_{2} \mathrm{H}_{3}$ peak at $893 \mathrm{~cm}^{-1}$ was not seen, and contributions from other species such as $\mathrm{CH}_{3} \mathrm{OH}$ and $\mathrm{CH}$ were not observed.

\subsection{Water layering}

Just before irradiation, the $\mathrm{H}_{2} \mathrm{O}$ column density in the ice bulk was $2.12 \times 10^{15}$ molecules $/ \mathrm{cm}^{2}$, measured from the peak at $\sim 3200 \mathrm{~cm}^{-1}$. During the experiment, a thin ice water grew up continually onto the $\mathrm{CH}_{4}$ target to a final column density 
$5.38 \times 10^{16}$ molecules $/ \mathrm{cm}^{2}$ ( 163 $\AA$ thickness). Figure $3 \mathrm{a}$ illustrates the increase in the water absorbance in the irradiated spectrum after about $12 \mathrm{~h}$ of irradiation by comparing with the virgin ice spectrum. If neglecting the water deposited during the FTIR acquisition (when the ion beam was stopped), these numbers correspond to a net deposition rate under irradiation of $1.21 \times 10^{12} \mathrm{H}_{2} \mathrm{O}$ molecules $/ \mathrm{cm}^{2} \mathrm{~s}$, i.e., to a net deposition yield (the balance between the layering yield, $L$, and the sputtering yield, $\left.Y_{\mathrm{S}}\right)$ of about $L-Y_{\mathrm{S}}=1206$ water molecules/projectile. Relevant comments on the water layering follow.

(i) The water layer practically does not interfere on the projectile interaction with $\mathrm{CH}_{4}$ in the bulk. Indeed, at the end of the irradiation, the water ice thickness has increased by 50 monolayers, which reduces the kinetic energy loss of the oxygen projectiles by only $2.2 \mathrm{keV}$.

(ii) Chemical reactions may occur in the $\mathrm{H}_{2} \mathrm{O}-\mathrm{CH}_{4}$ interface, producing hybrid species such as $\mathrm{H}_{2} \mathrm{CO}_{2}$ and $\mathrm{CH}_{3} \mathrm{OH}$. However, the IR peaks of these species are not observed in the current experiment even after high fluence irradiation. Other hybrid species such as $\mathrm{CO}_{2}$ and $\mathrm{CO}$ can be formed at the interface. Although very small quantities of $\mathrm{CO}_{2}$ and $\mathrm{CO}$ were observed in the virgin $\mathrm{CH}_{4}$ ice, it should be noted in Fig. 3a that the amount of $\mathrm{CO}_{2}$ after irradiation is much higher than the initial impurities in the sample.

(iii) The existence layer of $\mathrm{H}_{2} \mathrm{O}$ ice on top of the $\mathrm{CH}_{4}$ target drastically inhibits the $\mathrm{CH}_{4}$ sputtering: the emission energy of the sputtered species lies in the eV range (see e.g., Pereira 1997; Jalowy et al. 2004), so they are not expected to traverse even thin $\mathrm{H}_{2} \mathrm{O}$ layers. Actually this brings a convenient simplification to the analysis, since the sputtering contribution can be eliminated from the mathematical description, as shown in Eq. (2) by neglecting sputtering yield $Y_{i}$.

\subsection{Cross section determination}

Figure 6 shows the evolution of $\mathrm{CH}_{4}$ column density as a function of $220 \mathrm{MeV}$ oxygen beam fluence. The decreasing $\mathrm{CH}_{4}$ column density is related to the formation of other species and to the sputtering induced by heavy ions (Seperuelo Duarte et al. 2009, 2010; Pilling et al. 2010). The behavior of these data is assumed to be described by the system of differential equations:

$$
\frac{\mathrm{d} N_{i}}{\mathrm{~d} F}=\sum_{j, i} \sigma_{\mathrm{f}, i j} N_{j}+L_{i}-\sigma_{\mathrm{d}, i} N_{i}-Y_{i} \Omega_{i}(F)
$$

where $N_{i}$ is the column density of molecular species $i, \sigma_{\mathrm{f}}$ and $\sigma_{\mathrm{d}}$ are their formation and destruction cross sections, $L_{i}$ and $Y_{i}$ are their layering and sputtering yields respectively, and $\Omega_{i}(F)$ is coverage of the species $i$ on the surface after the beam fluences $F$.

Concerning the current experiment, these differential equations can be simplified and solved analytically under the following approximations:

(i) The initial ice is formed by a single molecular species. The precursor molecule, $\mathrm{CH}_{4}$, is labeled $i=1$.

(ii) There is no layering of $\mathrm{CH}_{4}$ during irradiation $\left(L_{1}=0\right.$, but it does exist for water, an accumulative target surface contaminant as explained in Sect. 3.3).

(iii) Sputtering is neglected for $\mathrm{CH}_{4}$ and for its products: $Y_{i}=0$, although at the beginning of irradiation the surface water layer is not thick enough to prevent completely the
$\mathrm{CH}_{4}$ secondary emission. At any rate, the effect of sputtering on $N_{1}(F)$ would be more evident at high fluences owing to thickness reduction, which is not seen in the current data (Seperuelo Duarte et al. 2009, 2010).

(iv) To obtain a solvable system of equations we have to make the assumption that the formation of a given daughter species $(i=k)$ can be treated independently of the others; i.e., the projectile does not produce a daughter species from other pre formed daughter species: $\sigma_{\mathrm{f}, i j} \approx 0$, where $i$ and $j$ hold for two daughters. This is a reasonable assumption at the beginning of the radiation, when the column density of the daughter species is much lower than that of $\mathrm{CH}_{4}$, $N_{i} \ll N_{1}$.

Under such conditions, Eqs. (2) are reduced to

$\frac{\mathrm{d} N_{1}}{\mathrm{~d} F}=\sigma_{\mathrm{f}, 1 k} N_{k}-\sigma_{\mathrm{d}, 1} N_{1}$

$\frac{\mathrm{d} N_{k}}{\mathrm{~d} F}=\sigma_{\mathrm{f}, k 1} N_{1}-\sigma_{\mathrm{d}, k} N_{k}$

with the solutions

$$
\begin{aligned}
\frac{N_{1}(F)}{N_{1}(0)}= & {\left[\frac{\sigma_{\mathrm{d}, k}-\sigma_{\mathrm{d}, 1}}{\sigma_{\Delta}} \sinh \left(\frac{\sigma_{\Delta} F}{2}\right)+\cosh \left(\frac{\sigma_{\Delta} F}{2}\right)\right] } \\
& \times \exp \left(-\frac{\left(\sigma_{\mathrm{d}, 1}+\sigma_{\mathrm{d}, k}\right) F}{2}\right) \\
\frac{N_{k}(F)}{N_{1}(0)}= & \frac{2 \sigma_{\mathrm{f}, k 1}}{\sigma_{\Delta}} \sinh \left(\frac{\sigma_{\Delta} F}{2}\right) \exp \left(-\frac{\left(\sigma_{\mathrm{d}, 1}+\sigma_{\mathrm{d}, k}\right) F}{2}\right),
\end{aligned}
$$

where

$$
\sigma_{\Delta}^{2}=\left(\sigma_{\mathrm{d}, 1}-\sigma_{\mathrm{d}, k}\right)^{2}+4 \sigma_{\mathrm{f}, k 1} \sigma_{\mathrm{f}, 1 k},
$$

where $\sigma_{f, 1 k}$ is the formation cross-section of $\mathrm{CH}_{4}$ from the $k$ species. Inversely, $\sigma_{\mathrm{f}, k 1}$ is the formation cross-section of $k$ species from $\mathrm{CH}_{4}$, and $\sigma_{\mathrm{d}, 1}$ is the destruction cross-section of $\mathrm{CH}_{4}$, whereas $\sigma_{\mathrm{d}, k}$ is the destruction cross-section of $k$ species. The data were fitted by using the Eqs. (4). To obtain a formation cross section of $\mathrm{CH}_{4}\left(\sigma_{\mathrm{f}, 1 k}\right)$, only the most abundant daughter species $\left(\mathrm{C}_{2} \mathrm{H}_{6}\right)$ has been considered, and this value is reported as $\sigma_{\mathrm{f}}$ in the Table 3 .

It is worth noting that, for low fluences, Eq. (4b) can be expanded into

$\frac{N_{k}(F)}{N_{1}(0)} \approx \sigma_{\mathrm{f}, k 1}\left[F-\frac{\sigma_{\mathrm{d}, 1}+\sigma_{\mathrm{d}, k}}{2} F^{2}\right]$

or transformed into

$\frac{N_{k}(F)}{N_{1}(0)} \approx \sigma_{\mathrm{f}, k 1}\left[\frac{1-\exp \left[-\left(\sigma_{\mathrm{d}, 1}+\sigma_{\mathrm{d}, k}\right) F\right]}{\left[\sigma_{\mathrm{d}, 1}+\sigma_{\mathrm{d}, k}\right]}\right]$.

Equation (4c) shows that the initial slope of the column density determines the formation cross section of the daughter molecules, while the curvature of the $N_{k}(F)$ function depends on the precursor-daughter average dissociation cross section. Equation (4d) shows that $N_{k}(F) / N_{1}(0) \propto\left(1-\exp \left(-\sigma_{\mathrm{f}, k 1} F\right)\right)$ or $N_{k}(F) / N_{1}(0) \propto\left(1-\exp \left(-\sigma_{\mathrm{d}, k} F\right)\right)$ are not the right functions for determining $\sigma_{\mathrm{f}, k 1}$ or $\sigma_{\mathrm{d}, k}$ from the fitting of the daughter's data over a wide fluence range. Equations (4a) and (4b) were used to get the values of the destruction and formation cross sections of $\mathrm{CH}_{4}$ and their daughters, which are presented in Table 3 . The 
A. L. F. de Barros et al.: Cosmic ray impact on astrophysical ices

Table 3. Formation $\left(\sigma_{\mathrm{f}}\right)$ and destruction $\left(\sigma_{\mathrm{d}}\right)$ cross-sections, as well as the $G$ of the $\mathrm{CH}_{4}$ and its daughters.

\begin{tabular}{llllll}
\hline \hline Molecule & $\sigma_{\mathrm{f}}\left(10^{-15} \mathrm{~cm}^{2}\right)$ & $\sigma_{\mathrm{d}}\left(10^{-15} \mathrm{~cm}^{2}\right)$ & $\sigma_{\mathrm{f}} / \sigma_{\mathrm{d}}$ Ratio & $G$ formation & $G$ destruction \\
\hline $\mathrm{CH}_{4}$ & 1.4 & 3.8 & 0.368 & 1.83 & 4.97 \\
\hline $\mathrm{C}_{2} \mathrm{H}_{2}$ & 0.12 & 1.8 & 0.006 & 0.157 & 23.53 \\
$\mathrm{C}_{2} \mathrm{H}_{4}$ & 0.15 & 1.1 & 0.014 & 0.196 & 14.38 \\
$\mathrm{C}_{2} \mathrm{H}_{6}$ & 1.20 & 3.5 & 0.343 & 1.568 & 4.57 \\
$\mathrm{C}_{3} \mathrm{H}_{8}$ & 0.06 & - & - & 0.078 & - \\
$\mathrm{CH}_{3}$ & 0.25 & 40.0 & 0.006 & 0.327 & 52.91 \\
\hline
\end{tabular}

Notes. $G=100 \mathrm{eV} \sigma / S$; where: $S_{n+e}(220 \mathrm{MeV}$ oxygen beam $)=76.5 \times 10^{15} \mathrm{eV} /\left(\right.$ molecule $\left./ \mathrm{cm}^{2}\right)$.

Table 4. Summary of column density variation of the observed species: destruction and formation yields at the end, with a fluence of $4.29 \times$ $10^{13}$ ions $\mathrm{cm}^{-2}$.

\begin{tabular}{llll}
\hline \hline Species & $\begin{array}{l}\text { Wavenumber } \\
\left(\mathrm{cm}^{-1}\right)\end{array}$ & $\begin{array}{l}\text { Change in column density } \\
\text { over irradiation }\left(\text { molecules } \mathrm{cm}^{-2}\right)\end{array}$ & $\begin{array}{l}\text { Yield: number of molecules } \\
\text { destroyed or produced per ion }\end{array}$ \\
\hline $\mathrm{CH}_{4}$ & 4202 & $(-3.87 \pm 0.50) \times 10^{17}$ & -9021 \\
$\mathrm{C}_{2} \mathrm{H}_{6}$ & 821 & $(9.89 \pm 0.50) \times 10^{16}$ & 2305 \\
$\mathrm{C}_{3} \mathrm{H}_{8}$ & 2962 & $(1.08 \pm 0.50) \times 10^{16}$ & 252 \\
$\mathrm{C}_{2} \mathrm{H}_{4}$ & 950 & $(9.11 \pm 0.50) \times 10^{15}$ & 212 \\
$\mathrm{CH}_{3}$ & 608 & $(5.71 \pm 0.50) \times 10^{15}$ & 133 \\
$\mathrm{C}_{2} \mathrm{H}_{2}$ & 736 & $(5.67 \pm 0.50) \times 10^{15}$ & 132 \\
\hline
\end{tabular}

evolution of column densities of the $\mathrm{CH}_{4}$ and of its most abundant daughters is shown in Fig. 6. The formation cross sections of each molecular species can be obtained from the slope of low fluences measurements, according to Eq. (4c), where $\sigma_{\mathrm{d}, 1}$ is kept constant for all fittings. This model is incomplete since it does not describe all chemical reactions, but does consider the $k$ species as the unique daughter formed from the irradiated molecule, which is not generally the case. However, its predictions should be close to the exact one if the $k$ species is the most abundant daughter. If many species are formed, then the sum of their formation cross sections should be equal to the destruction cross section of the precursor molecule, correcting for the chemical molecular balance. On the other hand, the relation between destruction cross sections of the daughters and the reformation cross section of the precursor needs to take all the species concentrations into account. Table 3 presents the formation cross-sections and radiochemical yields ( $G$-factors) for molecules identified in the present experiment. This factor allows comparison among chemical reaction yields produced by electrons, photons, and ions in the literature.

\subsection{Carbon budget}

The issue of the carbon budget is addressed by testing whether the column density of the methane destroyed can account for the column densities of the products. At the end of the irradiation we find that $3.87 \times 10^{17}$ methane molecules were destroyed per square centimeter, which is about $(14 \pm 1) \%$ of the original sample (Table 4). The total number of carbon atoms (per $\mathrm{cm}^{2}$ ) required to account for the observed column densities of the products at the end of the irradiation is obtained by adding each column density multiplied by the number of carbon in each species. Therefore for each one of the produced species we have $\mathrm{CH}_{3}=(5.71 \pm 0.50) \times 10^{15}, \mathrm{C}_{2} \mathrm{H}_{6}=(1.97 \pm 0.50) \times 10^{17}$, $\mathrm{C}_{2} \mathrm{H}_{4}=(1.82 \pm 0.50) \times 10^{16}, \mathrm{C}_{2} \mathrm{H}_{2}=(1.13 \pm 0.50) \times 10^{16}$, and $\mathrm{C}_{3} \mathrm{H}_{8}=(3.24 \pm 0.50) \times 10^{16}$. The total number of carbon required by the observed number of products is therefore $2.65 \times$ $10^{17}$ carbon atoms $\mathrm{cm}^{-2}$, which corresponds to much fewer than produced by the methane destroyed.

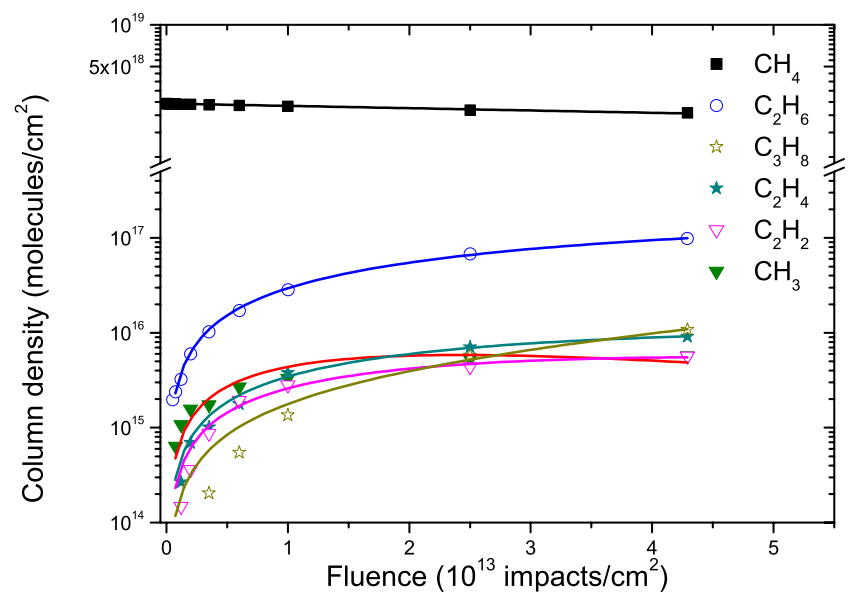

Fig. 6. Evolution of the column density of $\mathrm{CH}_{4}$ and the most abundant produced species. Solid curves are predictions given by Eqs. (4a) and (4b): the extracted cross sections are presented in Table 3.

Figure 7 shown the sum (line labeled with + ) of the column densities of carbon atoms of the most abundant daughters species of the $\mathrm{C}_{2} \mathrm{H}_{2}, \mathrm{C}_{2} \mathrm{H}_{4}, \mathrm{C}_{2} \mathrm{H}_{6}, \mathrm{CH}_{3}$, and $\mathrm{C}_{3} \mathrm{H}_{8}$. Those values were multiplied by the number of carbon atoms in the corresponding molecule as a function of fluence. For a direct comparison with the $\mathrm{CH}_{4}$ molecules destroyed (full dots), the column $N_{0}-N_{F}$ is plotted. The column density variations of those species were estimated for a fluence of $F=4.29 \times 10^{13}$ ion $\mathrm{cm}^{-2}$ (see Table 4). The destruction of $\mathrm{CH}_{4}$ gives $51 \%$ of $\mathrm{C}_{2} \mathrm{H}_{6}, 8.4 \%$ of $\mathrm{C}_{3} \mathrm{H}_{8}, 4.7 \%$ of $\mathrm{C}_{2} \mathrm{H}_{4}, 2.9 \%$ of $\mathrm{C}_{2} \mathrm{H}_{2}$, and $1.5 \%$ of $\mathrm{CH}_{3}$, a total of $68.5 \%$. Taking into account that no $\mathrm{CH}_{4}$ sputtering occurs in the current experiment, because of the water layer on the top of our $\mathrm{CH}_{4}$ ice, the rest of $31.5 \%$ of the destroyed $\mathrm{CH}_{4}$ can be related with some species which are not visible in our experiment. Possible candidates include $\mathrm{C}_{2}, \mathrm{C}_{2} \mathrm{H}_{3}, \mathrm{C}_{2} \mathrm{H}_{5}$, linear saturated and unsaturated hydrocarbons, as well as alkanes and polyclyclic aromatic hydrocarbons (PAHs) (Kaiser et al. 1992b,a). One important remark is that, if we choose the band $2975 \mathrm{~cm}^{-1}$ with the respective $A$-value from Gerakines et al. (1996) instead 


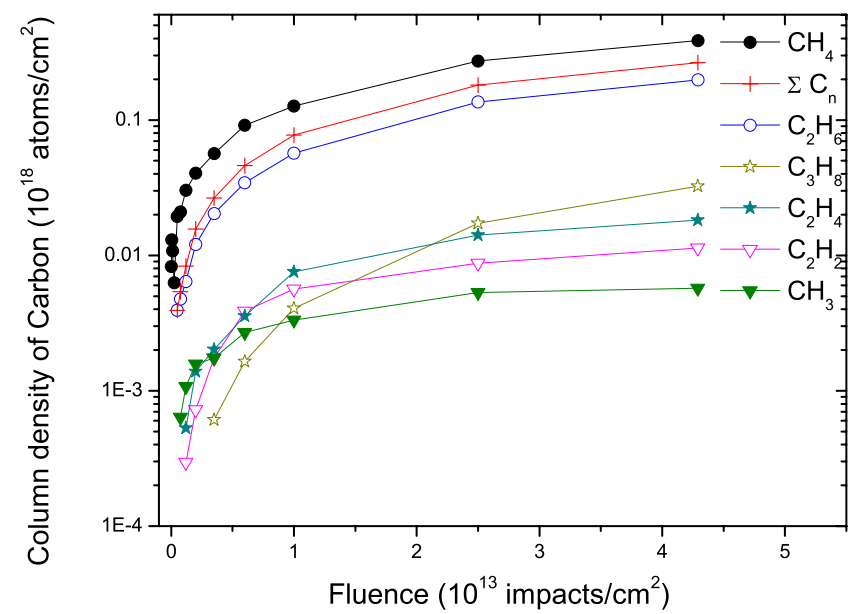

Fig. 7. Total and partial carbon column density as a function of beam fluence. The partial values are determined according to the carbon stoichiometry at the five most abundant species. The total value, which is the sum of all these curves, is labeled $\Sigma \mathrm{C}_{n}$ and the column density of $\mathrm{CH}_{4}$ was plotted using the expression $N_{0}-N_{F}$.

of the band $821 \mathrm{~cm}^{-1}$ adopted by Kaiser et al. (1996) and Bennett et al. (2006), the produced values $\mathrm{C}_{2} \mathrm{H}_{6}$ increase to $(4.42 \pm 0.50) \times 10^{17}$, meaning that the destruction of $\mathrm{CH}_{4}$ is less than the creation of $\mathrm{C}_{2} \mathrm{H}_{6}$, and the carbon budget will not be conserved. This remark shows that the judicious choice of coherent $A$-values is important, because otherwise the abundance ratio may be incorrect, hence the formation cross section values. The column density calculation (or internal normalization) using different bands of the same transition is useful for minimizing this problem.

\section{Astrophysical implications}

It is interesting to compare the effects of methane ice irradiation by oxygen $\mathrm{MeV}$ ions with other ion irradiation sources such as UV photons, protons, $\alpha$-particles, and electrons. The efficiencies of different irradiation sources for the destruction of the $\mathrm{CH}_{4}$ molecule and production of daughter species were calculated (the radiochemical yields $-G$-values). Data from previous works were digitized and the $G$-values were calculated taking the initial slopes of the column density curve as a function of the radiation dose. In present experiments for oxygen ions, $G\left(\mathrm{CH}_{4}\right)=$ 5.0 molec $(100 \mathrm{eV})^{-1}$, is nearly one order of magnitude more efficient for destroying methane than $7.3 \mathrm{MeV}$ protons, 0.6 molec $(100 \mathrm{eV})^{-1}$, or $9 \mathrm{MeV} \alpha$-particles, $0.9(100 \mathrm{eV})^{-1}$ (Kaiser \& Roessler 1998). The values of $G\left(\mathrm{CH}_{4}\right)=2.8 \mathrm{molec}(100 \mathrm{eV})^{-1}$, for irradiation with $30 \mathrm{keV} \mathrm{He}$, and 1.2 molec $(100 \mathrm{eV})^{-1}$, for UV (10.2 eV photons), were estimated from Baratta et al. (2002). These results can be easily understood by considering the amount of energy transferred to the methane ices by each ion as given by the electronic stopping power: $76.5(220 \mathrm{MeV} \mathrm{O})$, 27.5 (30 keV $\alpha$-particles), 20.3 (9.0 MeV $\alpha$-particles), and 2.0 (7.3 MeV protons), in units of $\times 10^{-15} \mathrm{eV} \mathrm{molec}-1 \mathrm{~cm}^{2}$. It is important to note that $30 \mathrm{keV} \mathrm{He}^{+}$ions are able to transfer an additional amount of $1.7 \times 10^{-15} \mathrm{eV} \mathrm{molec}^{-1} \mathrm{~cm}^{2}$ due to nuclear stopping. We also estimated $G\left(\mathrm{CH}_{4}\right)=4.4(100 \mathrm{eV})^{-1}$ for $5 \mathrm{keV}$ electrons irradiation Bennett et al. (2006), which shows that they are as efficient as oxygen ions for destroying methane ice.

It is worth mentioning that $G$-values from daughter species can only be compared relatively, since they are greatly dependent on the $A$-values (and band) adopted. This is not the case for $\mathrm{CH}_{4}$, as long as absorbance is linearly related to the column density, which was assumed for all cases in the analysis above. In addition, Kaiser \& Roessler (1998) and Bennett et al. (2006) used Reflection Absorption IR Spectroscopy (RAIRS) and $A$ values from transmission IR spectroscopy with no correction by "surface selection rule". Therefore, absolute $G$-values should be compared with caution. For instance, $G\left(\mathrm{C}_{2} \mathrm{H}_{6}\right)$ from Kaiser \& Roessler (1998), $1.0(100 \mathrm{eV})^{-1}$ (proton) and $1.3(100 \mathrm{eV})^{-1}(\alpha-$ particles), and Bennett et al. (2006), $4.0(100 \mathrm{eV})^{-1}$ (electrons), are strikingly high in comparison with $G\left(\mathrm{CH}_{4}\right)$. In the cases of both experiments from Kaiser \& Roessler (1998), $G\left(\mathrm{C}_{2} \mathrm{H}_{6}\right)$ are higher than $G\left(\mathrm{CH}_{4}\right)$, which is impossible in principle. A relative comparison between $G$-values from daughter species shows subtle behavior on the efficiencies of form $\mathrm{C}_{2} \mathrm{H}_{4}$ and $\mathrm{C}_{2} \mathrm{H}_{2}$. The efficiency of forming $\mathrm{C}_{2} \mathrm{H}_{2}$ compared to $\mathrm{C}_{2} \mathrm{H}_{4}$ seems to increase with the energy (or mass) of the projectile. Electrons, on the other hand, seem to be very inefficient at forming $\mathrm{C}_{2} \mathrm{H}_{2}$ relative to $\mathrm{C}_{2} \mathrm{H}_{4}$.

The present results give information about the radiolysis occurring inside dense molecular clouds, where temperatures can be as low as $10 \mathrm{~K}$ and molecules condense on the surface of dust particles to form ice mantles. The densities of these clouds $\left(\sim 10^{6}\right.$ atoms $\left./ \mathrm{cm}^{3}\right)$ are high enough to prevent the penetration of UV photons deep inside them. However, ionization of atoms and molecules by cosmic rays within the cloud produce an internal UV radiation flux of $10^{3}$ photons $/ \mathrm{cm}^{2} \mathrm{~s}$ (Prasad \& Tarafdar 1983). Energetic cosmic rays have higher penetration depths than UV photons and can trigger chemical reactions throughout an entire ice mantle.

We are now in a position to estimate how many $\mathrm{CH}_{4}$ and $\mathrm{C}_{2} \mathrm{H}_{6}$ molecules are destroyed and formed in a dense cloud during its typical life of $100 \mathrm{Myr}$. The flux of $220 \mathrm{MeV}$ oxygen cosmic rays is $\left(\phi=1.37 \times 10^{-4}\right.$ particles $\left./ \mathrm{cm}^{2} \mathrm{~s}\right)$ (Shen et al. 2004). During a typical cloud's life, $4.32 \times 10^{11}$ particles $/ \mathrm{cm}^{2}$ penetrate the cloud. From the present work (Table 5) the number of $\mathrm{CH}_{4}$ destroyed for a $0.1 \mu \mathrm{m}$ thick ice can be estimated as $2.2 \times$ $10^{14}$ molecules $/ \mathrm{cm}^{2}$, and a total of $6 \times 10^{13}$ molecules $/ \mathrm{cm}^{2}$ of $\mathrm{C}_{2} \mathrm{H}_{6}$ would be formed. The column density values are obtained by multiplying the yield values, normalized to $0.1 \mu \mathrm{m} \mathrm{CH}_{4}$ thick ice, by GCR fluence. Comparable results for other energetic particles are also included in this table. The values shown in Table 5 are far from completely describe the whole scenario. Other factors should be taken into account.

(i) In this work, only the results obtained for $220 \mathrm{MeV} \mathrm{O}$, 7.3 MeV H and 9.0 MeV He beams are discussed. To determine the total number of destruction or formation of molecules in ISM by energetic particles from cosmic rays, it is necessary to integrate the contributions of all projectiles over their entire energy range. Therefore, more laboratory experiments should be performed to determine the cross sections as a function of projectile energy.

(ii) In the interstellar medium, the dust ice mantles are composed of mixtures of many different species. This complexity is obviously not described by Eqs. (4a) and (4b). Therefore, theoretical efforts are necessary to solve Eq. (2) for realistic cases.

\section{Summary}

The interaction of $220 \mathrm{MeV}$ oxygen ions with pure $\mathrm{CH}_{4}$ ice has been studied. This projectile is one of the components of HGCR, and methane is a common molecule in the astrophysical environment. The results demonstrate that the $\mathrm{MeV}$ ion irradiation leads to production of $\mathrm{CH}_{3}$ and synthesis of $\mathrm{C}_{2} \mathrm{H}_{2}, \mathrm{C}_{2} \mathrm{H}_{4}, \mathrm{C}_{2} \mathrm{H}_{6}$, 
A. L. F. de Barros et al.: Cosmic ray impact on astrophysical ices

Table 5. Destruction of $\mathrm{CH}_{4}$ and formation of $\mathrm{C}_{2} \mathrm{H}_{6}$ molecules due to interaction with different projectiles inside a dense molecular cloud aged 100 Myr.

\begin{tabular}{|c|c|c|c|c|c|c|c|}
\hline Projectile & $\begin{array}{l}\text { GCR } \\
\text { flux } \\
\text { (particles/ } \\
\mathrm{cm}^{2} \mathrm{~s} \text { ) }\end{array}$ & $\begin{array}{l}\text { GCR } \\
\text { fluence } \\
\text { (particle/ } \\
\mathrm{cm}^{2} \text { ) }\end{array}$ & $\begin{array}{l}\text { Yield } \\
\left(\mathrm{CH}_{4}\right. \\
\text { molecule/ } \\
\text { impact })\end{array}$ & $\begin{array}{l}\text { Column } \\
\text { density } \\
\left(10^{15} \mathrm{CH}_{4}\right. \\
\left.\mathrm{molec} / \mathrm{cm}^{2}\right)\end{array}$ & $\begin{array}{l}\text { Yield } \\
\left(\mathrm{C}_{2} \mathrm{H}_{6}\right) \\
\text { molecule/ } \\
\text { impact })\end{array}$ & $\begin{array}{l}\text { Column } \\
\text { density } \\
\left(10^{15} \mathrm{C}_{2} \mathrm{H}_{6}\right. \\
\left.\text { molec } / \mathrm{cm}^{2}\right)\end{array}$ & Ref. \\
\hline UV (10.2 eV photons) & $1.00 \times 10^{3}$ & $3.15 \times 10^{18}$ & 0.044 & 139 & 0.003 & 10.7 & 1 \\
\hline $\mathrm{H}^{+}(7.3 \mathrm{MeV})$ & $3.18 \times 10^{-2}$ & $1.00 \times 10^{14}$ & $2.8^{*}$ & 0.28 & $3.1^{*}$ & 0.31 & 2 \\
\hline $\mathrm{He}^{+}(9.0 \mathrm{MeV})$ & $1.60 \times 10^{-3}$ & $5.03 \times 10^{12}$ & 33.0 & 0.17 & 16.8 & 0.08 & 2 \\
\hline${ }^{16} \mathrm{O}^{+7}(220 \mathrm{MeV})$ & $1.37 \times 10^{-4}$ & $4.32 \times 10^{11}$ & 506.8 & 0.22 & 129.5 & 0.06 & 3 \\
\hline
\end{tabular}

Notes. ${ }^{(*)}$ Table 13 of Kaiser \& Roessler (1998) values are attached with large experimental errors: it should be reminded that the $\mathrm{C}_{2} \mathrm{H}_{6}$ formation yield must be always lower than half of the $\mathrm{CH}_{4}$ destruction yield.

References. ${ }^{1}$ Baratta et al. (2002), ${ }^{2}$ Kaiser \& Roessler (1998), ${ }^{3}$ this work.

and $\mathrm{C}_{3} \mathrm{H}_{8}$. The destruction cross section of $\mathrm{CH}_{4}$ has been determined, as well as the formation cross sections of the observed daughters: $\mathrm{CH}_{3}, \mathrm{C}_{2} \mathrm{H}_{2}, \mathrm{C}_{2} \mathrm{H}_{4}, \mathrm{C}_{2} \mathrm{H}_{6}$, and $\mathrm{C}_{3} \mathrm{H}_{8}$. The most abundant daughter produced is $\mathrm{C}_{2} \mathrm{H}_{6}$. Concerning ion beams, oxygen is nearly one order of magnitude more efficient for destroying methane than protons or $\alpha$ particles. We emphasize that the $A$-values of precursor and daughter bands for estimating of column densities have to be consistently chosen in order to obtain reliable and correct formation cross section values and a valid carbon budget.

Acknowledgements. This work was supported by the region of "BasseNormandie" (France) and by the French-Brazilian exchange program CAPESCOFECUB. It is a pleasure to thank Th. Been and J. M. Ramillon for technical support. The experiment was performed at the GANIL facility in Caen, France. We acknowledge the partial support of Brazilian agencies CNPq and FAPERJ.

\section{References}

Baratta, G. A., Leto, G., \& Palumbo, M. E. 2002, A\&A, 384, 343

Bennett, C. J., Jamieson, C. S., Osamura, Y., \& Kaiser, R. I. 2006, ApJ, 653, 792 Bergin, E. A., Langer, W. D., \& Goldsmith, P. F. 1995, ApJ, 441, 222

Boogert, A. C. A., Schutte, W. A., Tielens, A. G. G. M., et al. 1996, A\&A, 315, L377

Bringa, E. M., \& Johnson, R. E. 2004, ApJ, 603, 159

Brown, M. E., Bouchez, A. H., \& Griffith, C. A. 2002, Nature, 420, 795

Brown, M. E., Trujillo, C. A., \& Rabinowitz, D. L. 2005, ApJ, 635, L97

Brunetto, R., Caniglia, G., Baratta, G. A., \& Palumbo, M. E. 2008, ApJ, 686, 1480

Chapados, C., \& Cabana, A. 1972, Can. J. Chem., 50, 3521

Charnley, S. B., Rodgers, S. D., \& Ehrenfreund, P. 2001, A\&A, 378, 1024

Collado, V., Farenzena, L., Ponciano, C., Silveira, E., \& Wien, K. 2004, Surf. Sci., 569, 149

Cruikshank, D. P., Roush, T. L., Owen, T. C., et al. 1993, Science, 261, 742

Ehrenfreund, P., Gerakines, P. A., Schutte, W. A., van Hemert, M. C., \& van Dishoeck, E. F. 1996, A\&A, 312, 263

Farenzena, L. S., Iza, P., Martinez, R., et al. 2005, Earth Moon and Planets, 97, 311

Gerakines, P. A., Schutte, W. A., \& Ehrenfreund, P. 1996, A\&A, 312, 289

Gerakines, P. A., Bray, J. J., Davis, A., \& Richey, C. R. 2005, ApJ, 620, 1140

Gibb, E. L., Whittet, D. C. B., Boogert, A. C. A., \& Tielens, A. G. G. M. 2004, ApJS, 151, 35
Griffith, C. A., Owen, T., Miller, G. A., \& Geballe, T. 1998, Nature, 395, 575 Hasegawa, T. I., \& Herbst, E. 1993, MNRAS, 261, 83

Jalowy, T., Farenzena, L. S., Ponciano, C. R., et al. 2004, Surface Science, 557, 91

Kaiser, R. I., \& Roessler, K. 1998, ApJ, 503, 959

Kaiser, R. I., Lauterwein, J., Müller, P., \& Roessler, K. 1992a, Nucl. Instrum. Meth. Phys. Res. B, 65, 463

Kaiser, R. I., Mahfouz, R. M., \& Roessler, K. 1992b, Nucl. Instrum. Meth. Phys. Res. B, 65, 468

Lacy, J. H., Carr, J. S., Evans, II, N. J., et al. 1991, ApJ, 376, 556

Lanzerotti, L. J., Brown, W. L., \& Marcantonio, K. J. 1987, ApJ, 313, 910

Leger, A., Jura, M., \& Omont, A. 1985, A\&A, 144, 147

Licandro, J., Pinilla-Alonso, N., Pedani, M., et al. 2006, A\&A, 445, L35

Lindal, G. F., Lyons, J. R., Sweetnam, D. N., Eshleman, V. R., \& Hinson, D. P. 1987, J. Geophys. Res., 92, 14987

Martinez, R., Ponciano, C., Farenzena, L., et al. 2006, Int. J. Mass Spectrom., 253, 112

McKay, C. P., Martin, S. C., Griffith, C. A., \& Keller, R. M. 1997, Icarus, 129, 498

Moore, M. H., \& Hudson, R. L. 1998, Icarus, 135, 518

Moore, M. H., \& Hudson, R. L. 2003, Icarus, 161, 486

Mulas, G., Baratta, G. A., Palumbo, M. E., \& Strazzulla, G. 1998, A\&A, 333, 1025

Nguyen, T. K., Ruffle, D. P., Herbst, E., \& Williams, D. A. 2002, MNRAS, 329, 301

Öberg, K. I., Fuchs, G. W., Awad, Z., et al. 2007, ApJ, 662, L23

Öberg, K. I., Boogert, A. C. A., Pontoppidan, K. M., et al. 2008, ApJ, 678, 1032

Öberg, K. I., van Dishoeck, E. F., \& Linnartz, H. 2009, A\&A, 496, 281

Owen, T. C., Roush, T. L., Cruikshank, D. P., et al. 1993, Science, 261, 745

Pearl, J., Ngoh, M., Ospina, M., \& Khanna, R. 1991, J. Geophys. Res., 96, 17477

Pereira, J. 1997, Surf. Sci., 390, 158

Pilling, S., Seperuelo Duarte, E., da Silveira, E. F., et al. 2010, A\&A, 509, A87

Ponciano, C., Martinez, R., Farenzena, L., et al. 2006, J. Am. Soc. Mass Spectrom., 17, 1120

Prasad, S. S., \& Tarafdar, S. P. 1983, ApJ, 267, 603

Seperuelo Duarte, E., Boduch, P., Rothard, H., et al. 2009, A\&A, 502, 599

Seperuelo Duarte, E., Domaracka, A., Boduch, P., et al. 2010, A\&A, 512, A71

Shematovich, V. I., Shustov, B. M., \& Wiebe, D. S. 1997, MNRAS, 292, 601

Shen, C. J., Greenberg, J. M., Schutte, W. A., \& van Dishoeck, E. F. 2004, A\&A, 415, 203

Smith, B. A., Soderblom, L. A., Banfield, D., et al. 1989, Science, 246, 1422

Willacy, K., \& Millar, T. J. 1998, MNRAS, 298, 562

Willacy, K., \& Williams, D. A. 1993, MNRAS, 260, 635

Ziegler, J. F., Biersack, J. P., \& Littmark, U. 1985, The Stopping and Range of Ions in Solids (New York: Permagon) 